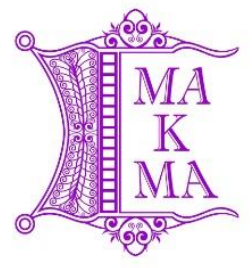

Majalah Kesehatan Masyarakat Aceh (MaKMA) http://ojs.serambimekkah.ac.id/index.php/makma

\title{
INOVASI PROGRAM PENYU RAJA SEBAGAI ALTERNATIF PENINGKATAN PROMOSI KESEHATAN DI PUSKESMAS SONGGON KABUPATEN BANYUWANGI
}

\author{
Wahyu Febriawan ${ }^{\bowtie}$, Jayanti Dian Eka Sari \\ Departemen Promosi Kesehatan dan Ilmu Perilaku, Program Studi S1 Kesehatan Masyarakat, \\ PSDKU Universitas Airlangga di Banyuwangi \\ ${ }^{\otimes}$ Alamat Korespondensi: Desa Kemiri, Kecamatan Singojuruh, Banyuwangi/ 0885894476012
}

\begin{abstract}
ABSTRAK
Tahun 2019 program promkes Puskesmas Songgon dari target 56\% rumah tangga sehat yang memenuhi 10 indikator PHBS masih tercapai $45 \%$. Belum adanya penyuluhan kesehatan di rawat jalan Puskesmas Songgon kemungkinan dapat mempengaruhi belum tercapainya target dari Puskesmas, sehingga perlu dilakukan pemberdayaan petugas kesehatan di Puskesmas. Kegiatan ini bertujuan untuk mengembangkan inovasi program Penyu Raja (Penyuluhan di Rawat Jalan) dengan cara memberdayakan petugas kesehatan di Puskesmas Songgon. Sasaran pada pemberdayaan terbagi menjadi 3 yakni sasaran primer adalah petugas kesehatan, sasaran sekunder adalah pengunjung rawat jalan, dan sasaran tersier adalah kepala Puskesmas Songgon. Metode pemberdayaan dengan role model, diawali dengan role model memberikan stimuasi kepada petugas kesehatan Puskesmas Songgon, kemudian petugas kesehatan diajak kerjasama untuk melakukan penyuluhan di rawat jalan secara bergantian dan sesuai jadwal. Adapun tahapan pemberdayaan meliputi: advokasi, penyusunan jadwal, pelaksanaan (role model), pendampingan dan evaluasi. Hasil dari pemberdayaan ini yaitu petugas kesehatan Puskesmas Songgon mampu mengembangkan inovasi penyuluhan dalam gedung dengan memanfatkan sumberdaya yang ada di Puskesmas. Pemberdayaan ini sudah memenuhi target keberhasilan kegiatan yakni $45 \%$ petugas kesehatan mau dan mampu melakukan penyuluhan di rawat jalan Puskesmas Songgon. Harapannya petugas kesehatan lebih aktif untuk melakukan penyuluhan di rawat jalan dan adanya peraturan yang tegas dari pemegang kebijakan.
\end{abstract}

Kata Kunci: Pemberdayaan, Penyuluhan, Promosi Kesehatan.

Riwayat Artikel

Diterima : : 16 Mei 2019

Disetujui : : 14 Juni 2019

Dipublikasi : : 31 Juli 2019 
THE INNOVATION OF PENYU RAJA PROGRAM AS AN ALTERNATIVE TO IMPROVE HEALTH PROMOTION IN PUSKESMAS SONGGON OF BANYUWANGI REGENCY

\begin{abstract}
In 2019 the health promotion program of Puskesmas Songgon did not reach the target. The target is 56\%, but Puskesmas Songgon still reached $45 \%$ in healthy households that fulfilled 10 health indicators. The absence of health counseling in outpatient Puskesmas Songgon possibility can affect the achievement of targets from the Puskesmas, so that it was necessary to empower health workers at the Puskesmas Songgon. This activity aimed to develop the innovation of the Penyu Raja program (Outreach in Outpatient Services) by empowering health workers at Puskesmas Songgon. The target of this empowerment was divided into 3: the primary target was Puskesmas Songgon health workers, the secondary target was visitors to Puskesmas Songgon outpatient, and the tertiary target was the head of Puskesmas Songgon. The empowerment method used was role model, starting with role models provides stimulation to Puskesamas Songgon health workers, that health workers at Puskesmas Songgon were invited to collaborate to conduct outreach counseling basis alternately and on schedule. The stages of empowerment included: advocacy, scheduling, implementation (role models), assistance, and evaluation. The result of this empowerment was that health workers at Puskesmas Songgon were able to develop counseling innovations in buildings by utilizing existing resources in the Puskesmas Songgon. This empowerment has fulfilled the target of success of this activity, and $45 \%$ of health workers want and are able to carry out counseling in outpatient of Puskesmas Songgon. The hope is health workers will be more active in conducting outpatient counseling and firm regulations from policy holders.
\end{abstract}

Keywords: Counseling, Empowerment, Health Promotion. 


\section{PENDAHULUAN}

Pembangunan kesehatan pada periode 2015-2019 adalah Program Indonesia Sehat dengan sasaran meningkatkan derajat kesehatan dan status gizi masyarakat melalui upaya kesehatan dan pemberdayaan masyarakat yang didukung dengan perlindungan finansial dan pemerataan pelayanan kesehatan. Program Indonesia Sehat dilaksanakan dengan 3 pilar utama yaitu paradigma sehat, penguatan pelayanan kesehatan dan jaminan kesehatan nasional; 1) pilar paradigma sehat dilakukan dengan strategi pengarusutamaan kesehatan dalam pembangunan, penguatan promotif \& preventif dan pemberdayaan masyarakat; 2) penguatan pelayanan kesehatan dilakukan dengan strategi peningkatan akses pelayanan kesehatan, optimalisasi sistem rujukan dan peningkatan mutu pelayanan kesehatan, menggunakan pendekatan continuum of care dan intervensi berbasis risiko kesehatan; 3) sementara itu jaminan kesehatan nasional dilakukan dengan strategi perluasan sasaran dan benefit serta kendali mutu dan kendali biaya ${ }^{[1]}$.

Puskesmas merupakan sebuah sarana penggerak pembangunan yang berwawasan kesehatan ${ }^{[2]}$. Berbagai pelayanan kesehatan yang diberikan oleh puskesmas diantaranya pelayanan kuratif (pengobatan), preventif (pencegahan), promotif (peningkatan kesehatan), dan rehabilitatif (pemulihan kesehatan). Pelayanan utama yang ditekankan oleh Puskesmas yakni pada bagian promotif dan preventif dengan program promosi kesehatan. Promosi kesehatan merupakan suatu proses untuk memampukan masyarakat dengan memelihara dan meningkatkan kesehatan mereka sendiri ${ }^{[3]}$. Salah satu bentuk strategi pemerintah untuk meningkatkan kemampuan masyarakat dalam memelihara dan meningkatkan kesehatannya yaitu Upaya Kesehatan Bersumber Masyarakat (UKBM).

Beberapa penyakit menular seperti Filariasis, Kusta, dan Frambusia menunjukkan kecenderungan meningkat dan penyakit Pes masih terdapat di sejumlah daerah. Sementara itu, prevalensi penyakit tidak menular seperti Penyakit Kardiovaskular, Hipertensi, Diabetes Mellitus dan Obesitas cenderung meningkat serta menunjukkan potensi yang semakin besar sebagai penyebab kematian [4]. Keadaan ini mengakibatkan adanya beban ganda dalam penanggulangan penyakit di Indonesia ${ }^{[5]}$. Rumah tangga yang telah mempraktikkan perilaku hidup bersih dan sehat (PHBS) baru mencapai 38,7\% [3]. Oleh sebab itu, Renstra Kementerian Kesehatan Tahun 2010-2014 mencantumkan target 70\% rumah tangga sudah mempratikkan PHBS pada tahun $2014{ }^{[6]}$. Dalam mengantisipasi perilaku masyarakat di Kecamatan Songgon yang belum menerapkan perilaku hidup bersih dan sehat, diperoleh target $56 \%$ rumah tangga sehat yang memenuhi 10 indikator PHBS masih tercapai $45 \%$, sehingga diperlukan peran promosi kesehatan, tidak hanya berfokus pada perubahan perilaku masyarakat saja ${ }^{[7]}$.

Berdasarkan capaian tersebut, maka diperlukan peningkatan promosi kesehatan untuk mencapai target tersebut. Puskesmas Songgon selama ini belum menerapkan promosi kesehatan di dalam gedung, adanya hanya mengundanghadirkan masyarakat ke Puskesmas yang kemudian diberikan penyuluhan. Puskesmas Songgon, selama ini belum melaksanakan kegiatan penyuluhuan di rawat jalan belum pernah dilakukan oleh Puskesmas Songgon. Sedangkan untuk kegiatan promosi kesehatan di luar gedung sudah berjalan dengan baik. Sehingga diperlukan upaya peningkatan 
promosi kesehatan di dalam gedung terutama di rawat jalan, agar berjalan selaras penyuluhan didalam gedung maupun diluar gedung. Berdasarkan permasalahan diatas, maka upaya yang dapat dilakukan yakni memberdayakan petugas kesehatan di Puskesmas

\section{METODE}

Metode yang digunakan dalam pemberdayaan ini adalah teknik pemicuan atau stimulasi untuk menggugah petugas kesehatan di Puskesmas Songgon, salah satu teknik yang digunakan yakni dengan role model. Adapun kegiatan role model ini meliputi perencanaan, pelaksanaan hingga monitoring dan evaluasi promosi kesehatan di dalam gedung. Tahap ini petugas kesehatan dituntut untuk peka terhadap kondisi Puskesmas, serta masyarakat yang memanfaatkan pelayanan kesehatan di Puskesmas Songgon. Salah satu upaya yang dapat dilakukan untuk melatih kepekaan tersebut yakni dengan mengajarkan petugas kesehatan terkait dengan mengidentifikasi sumber daya yang dimiliki Puskesmas Songgon, kemudian dilakukan inovasi pengembangannya sesuai dengan sumber daya yang dimilikinya. Pemberdayaan dilakukan sejak tanggal 14 Januari 2019 sampai dengan 02 Maret 2019 di ruang tunggu rawat jalan Puskesmas Songgon, waktu pelaksanaan yakni setiap hari pukul 07.30 WIB. Pemberdayaan ini melalui beberapa tahap, yaitu: advokasi, penyusunan jadwal, pelaksanaan (role model), pendampingan dan evaluasi. Tahapan proses pemberdayaan yang dilakukan diantaranya:

1. Advokasi: salah satu tahap awal untuk melakukan kegiatan pemberdayaan ini, advokasi dilakukan kepada penanggungjawab program promosi kesehatan dan kepala Puskesmas Songgon. Setelah
Songgon yang bertujuan untuk mengembangkan pelaksanaan inovasi program Penyu Raja (Penyuluhan di Rawat Jalan) di Puskesmas Songgon Banyuwangi

mendapatkan persetujuan, dilakukan advokasi kepada seluruh petugas kesehatan lainnya. Advokasi yang dilakukan ke penanggungjawab program promosi kesehatan yakni dengan meminta seluruh petugas kesehatan Puskesmas Songgon membuat SAP (Satuan Acara Penyuluhan) dan meminta untuk merencanakan jadwal penyuluhan. Kemudian advokasi kepada kepala Puskesmas Songgon berupa meminta untuk membuat kebijakan terkait dengan inovasi Penyu Raja (Penyuluhan di Rawat Jalan) bahwa seluruh petugas kesehatan harus melakukan penyuluhan di rawat jalan.

2. Penyusunan jadwal: pada tahap ini petugas kesehatan Puskesmas Songgon diajari untuk menyusun jadwal setiap harinya dengan topik bergantian dan disusun dalam setahun kedepan.

3. Pelaksanaan (role model): pada tahap ini awalnya role model mengajarkan mengidentikasi sumber daya yang ada di Puskesmas, penyusunan jadwal penyuluhan secara bergantian setiap harinya, pembuatan SAP (Satuan Acara Penyuluhan), kemudian pelaksanaan penyuluhan, pendampingan untuk melihat berjalannya kegiatan ini, hingga monitoring kegiatan penyuluhannya dan evaluasi kegiatan penyuluhan di rawat jalan.

4. Pendampingan: pada tahap ini pendampingan dilakukan pada 
minggu kedua setelah dilakukan role model. Pendampingan dilakukan oleh role model untuk melihat atau menilai jalannya kegiatan penyuluhan di rawat jalan ini. Pendampingan dilaksanakan secara bertahap, yang nantinya akan dilepas untuk melakukan penyuluhan dengan mandiri. petugas kesehatan diminta untuk melakukan peyuluhan di rawat jalan secara bergantian setiap hari.

5. Evaluasi: evaluasi dilakukan tahap proses yakni dengan menilai atau melihat berjalannya kegiatan

\section{HASIL}

Kegiatan inovasi program Penyu Raja ini terdapat 3 sasaran sekaligus, yakni: sasaran primer, sasaran sekunder dan sasaran tersier. Sasaran primer pada pemberdayaan ini adalah petugas kesehatan Puskesmas Songgon, kemudian sasaran sekundernya adalah Pengunjung rawat jalan Puskesmas Songgon, serta sasaran tersier adalah pembuat kebjiakan di Puskesmas Songgon, dalam hal ini yakni Kepala Puskesmas. Sasaran primer petugas kesehatan Puskesmas Songgon dari pemberdayaan Penyu Raja.

Program promosi kesehatan yang telah dilaksanakan oleh Puskesmas Songgon sudah banyak yang tercapai yakni $100 \%$. Namun masih terdapat kegiatan yang belum memenuhi capaian yakni PHBS tatanan Rumah Tangga terkait dengan Rumah Tangga Sehat, masih terdapat kesenjangan sebesar 41,3\%. Program promosi kesehatan Puskesmas Songgon 2017 dan 2018, masih terjadi kesamaan pada kegiatan yang belum tercapai yakni Rumah Tangga Sehat ${ }^{[7]}$. Sehingga pada rencana usulan kegiatan yang diberikan oleh pemegang program promkes untuk meningkatkannya yakni melalui penyuluhan pada masyarakat dan penyuluhan, adanya hambatan, dan kecakapan penyampaian materinya. Selain itu, evaluasi output dilihat dari respon masyarakat terkait dengan penyuluhan dan respon dari petugas kesehatan yang sebagai sasaran pemberdayaan Penyu Raja ini. Target keberhasilan kegiatan ini yakni $40 \%$ dari 27 petugas kesehatan mau dan mampu melakukan penyuluhan di rawat jalan Puskesmas Songgon.

melakukan pemicuan kepada masyarakat. Selain itu, pemegang program promkes juga mencari akar dari penyebab masalah Rumah Tangga yang belum memenuhi kriteria sehat yakni salah satunya penyuluhan yang kurang maksimal, sosial budaya masyarakat yang sulit diubah, kualitas pendataan yang kurang maksimal, rendahnya tingkat pendidikan ${ }^{[7]}$.

Berdasarkan hasil wawancara dengan penanggungjawab program promkes, selama ini masih belum pernah ada kegiatan promosi kesehatan didalam gedung terutama penyuluhan di ruang tunggu pelayanan rawat jalan yang sasarannya pengunjung Puskesmas, hanya terdapat kegiatan penyuluhan yang mengundang hadirkan sasaran ke Puskesmas. Selain itu, dari pihak Puskesmas terutama penanggungjawab program promkes, terdapat kesalahan persepsi dengan kegiatan promosi kesehatan didalam gedung. Pihak Puskesmas memiliki persepsi bahwa yang dimaksud dengan promosi kesehatan didalam gedung yakni mengundang hadirkan sasaran masyarakat ke dalam gedung aula dan diberikan penyuluhan terkait dengan masalah kesehatan. Sehingga kegiatan penyuluhan di dalam gedung hanya 
dilakukan disaat adanya pertemuan di aula puskesmas, untuk pengunjung yang datang di Puskesmas tidak diberikan penyuluhan kelompok. Penyuluhan di rawat jalan belum pernah dilakukan hal ini dikarenakan belum pekanya petugas kesehatan terkait dengan sumberdaya yang ada di Puskesmas Songgon, sehingga fasilitas yang dapat digunakan sebagai media promosi kesehatan belum digunakan secara optimal. Fasilitas yang dimaksud seperti televisi di ruang tunggu, leaflet dan lain-lainnya.

Program inovasi yang diusulkan dan ditawarkan kepada penanggungjawab program promkes yaitu Penyuluhan di Rawat Jalan (Penyu Raja) yakni kependekan dari Penyuluhan di Rawat Jalan. Sesuai dengan kepanjngannya, kegiatan ini dilakukan di ruang tunggu pelayanan rawat jalan Puskesmas Songgon dengan memberikan informasi atau pengetahuan mengenai suatu masalah kesehatan mulai dari pengertian, penyebab, pencegahan hingga pengobatanya. Kegiatan ini dikonsep dengan mengajak kerjasama setiap pemegang program/kegiatan yang ada di Puskesmas Songgon untuk secara bergantian melakukan penyuluhan sesuai dengan jadwal yang sudah dibuat perbulan selama setahun yakni tahun 2019, dan jadwal tersebut ditempel pada mading Puskesmas Songgon. Informasi yang diberikan kepada pengunjung setiap hari berbeda-beda dan berurutan

\section{PEMBAHASAN}

Kegiatan inovasi Penyu Raja ini juga menerapkan beberapa strategi promkes yang dihasilkan dari piagam Ottawa (Ottawa Charter) tahun $1986^{[8]}$. Adapun strategi promkes yang diterapkan yaitu: sesuai dengan jadwal yang sudah disusun.

Pelaksanaan kegiatan ini dengan cara role model mengawali kegiatan penyuluhan di rawat jalan Puskesmas Songgon. Namun juga ada beberapa petugas kesehatan yang mulai melakukannya. Harapannya dari adanya kegiatan dan program inovasi di Puskesmas Songgon ini dapat memberikan dampak baik bagi pemegang program agar berpartisipasi secara aktif dan nyata untuk melakukan penyuluhan di ruang tunggu pelayanan rawat jalan Puskesmas Songgon seterusnya. Role model dibantu oleh penanggungjawab program promkes untuk melakukan advokasi kepada masing-masing pemegang program atau kegiatan yang ada di Puskesmas Songgon untuk berpartisipasi dalam kegiatan ini. Selain itu, masing-masing pemegang program/kegiatan juga diminta untuk membuat dan mengumpulkan SAP (Satuan Acara Penyuluhan) sebagai pedoman materi penyuluhan yang akan di sampaikan kepada pengunjung rawat jalan Puskesmas Songgon. Target keberhasilan dari kegiatan Penyu Raja (Penyuluhan di Rawat Jalan) ini yakni $40 \%$ dari 27 petugas kesehatan mau dan mampu melakukan penyuluhan di rawat jalan Puskesmas Songgon. Hasil dari pemberdayaan petugas kesehatan ini tercapai $45 \%$ atau 12 petugas kesehatan mau dan mampu melakukan penyuluhan di rawat jalan.

1. Kebijakan Berwawasan Kesehatan (Healthy Public Policy)

Suatu strategi promosi kesehatan yang ditujukan kepada pembuat kebijakan, agar mereka mengeluarkan kebijakan-kebijakan publik yang mendukung kesehatan $^{[8]}$. Kebijakan dalam 
usulan program ini adalah adanya dukungan dari kepala Puskesmas Songgon, dukungan ini dapat dilihat melalui persetujuan jadwal penyuluhan yang disusun bersama pemegang program promkes. Adanya kebijakan ini maka dapat memberikan dukungan untuk meningkatkan pengetahuan masyarakat mengenai kesehatan. Selain itu, kebijakan lain yakni dilarang merokok di kawasan Puskesmas Songgon dan apabila terdapat pengunjung yang merokok maka segenap karyawan Puskesmas wajib menegur. Hal ini menunjukkan bahwa adanya kebijakan yang mendukung kesehatan di lingkungan Puskesmas Songgon.

2. Lingkungan yang Mendukung (Supportive Environment)

Strategi ini berkaitan dengan Lingkungan yang mendukung di Puskesmas Songgon terkait dengan terciptanya lingkungan yang bersih dan mendukung diadakan kegiatan promosi kesehatan terutama penyuluhan di ruang tunggu rawat jalan. Lingkungan yang dimaksud adalah fasilitas yang ada diruang tunggu pelayanan rawat jalan. Role model memanfaatkan leaflet sebagai media promosi kesehatan saat dilakukan penyuluhan kepada pengunjung, selain itu role model memanfaatkan fasilitas televisi yang ada di ruang tunggu sebagai media kegiatan promosi kesehatan yang berupa audiovisual. Sehingga pasien selain menunggu antrian berobat di rawat jalan juga mendapatkan informasi kesehatan dan harapannya dapat meningkatan pengetahuan masyarakat mengenai masalah kesehatan. Kemudian lingkungan yang mendukung lainnya seperti adanya tempat sampah di setiap ruangan yang dibedakan menjadi sampah organik dan anorganik, ruang tunggu rawat jalan yang nyaman, toilet yang bersih, sarana untuk penyandang disabilitas, air bersih, washtafel di ruang tunggu pelayanan rawat jalan.

3. Reorientasi Pelayanan Kesehatan (Reorient Health Services)

Reorientasi pelayanan kesehatan tidak hanya melibatkan pemerintah lintas sektor saja, melainkan juga melibatkani pemberdayaan masyarakat ${ }^{[8]}$. Masyarakat harus diberdayakan agar mereka dapat berperan dan tidak hanya sebagai penerima layanan kesehatan saja melainkan penyelenggara pelayanan kesehatan $^{[8]}$. Hal tersebut dapat diimplementasikan dari kegiatan inovasi yang diusulkan yaitu mengajak masyarakat untuk mencegah masalah kesehatan melalui kegiatan penyuluhan yang dilakukan petugas kesehatan di ruang tunggu rawat jalan Puskesmas Songgon. Dengan adanya informasi yang disampaikan oleh petugas kesehatan Puskesmas, diharapankan masyarakat dapat berpartisipasi dalam penyelenggaraan pelayanan kesehatan melalui konsep pencegahan dan promosi kesehatan.

4. Ketrampilan Individu (Personal Skill)

Status kesehatan masyarakat akan terwujud apabila kesehatan individu ataupun kelompok dapat terwujud pula $^{[8]}$. Ketrampilan individu sangat penting dimililki oleh setiap orang. Hal ini guna untuk meningkatkan kemampuan 
individu dalam memelihara kesehatannya. Salah satu cara untuk meningkatkan keterampilan masyarakat yakni dengan memberikan informasi mengenai masalah kesehatan melalui penyuluhan di ruang tunggu pelayanan rawat jalan. Tujuan dari kegiatan tersebut ialah memberikan pemahaman kepada masyarakat yang berkunjung di rawat jalan Puskesmas Songgon terkait masalah kesehatan yanga dihadapi masyarakat sehari-hari.

5. Gerakan Mayarakat

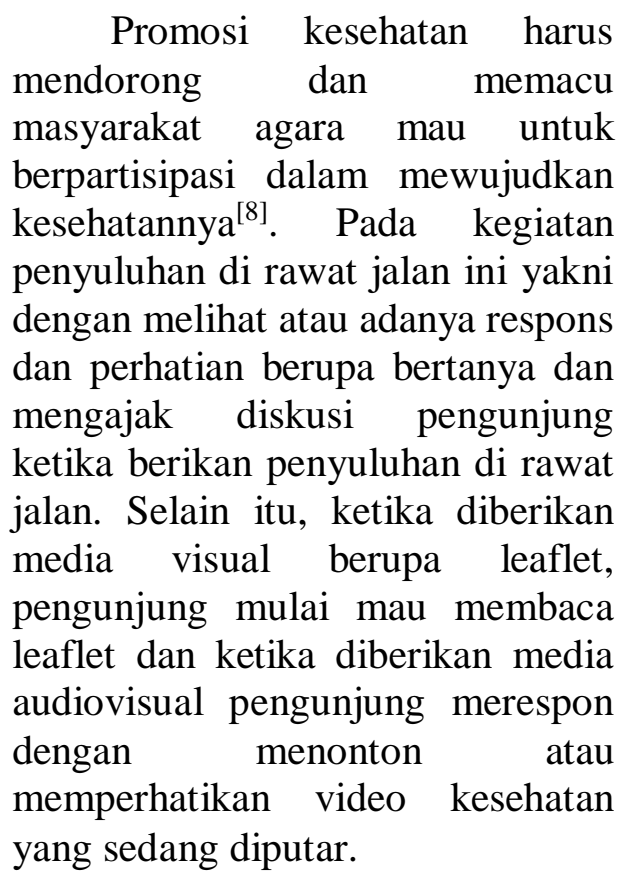

Kegiatan inovasi Penyu Raja tersebut dilaksanakan mulai tanggal 14 Januari 2019 yang bertempat di ruang tunggu pelayanan rawat jalan Puskesmas Songgon. Pelaksanaan kegiatan inovasi Penyu Raja dilakukan setiap hari pengunjung rawat jalan dan sebelum waktu pelayanan rawat jalan Puskesmas Songgon di mulai, yakni sekitar pukul 07.30 WIB sehingga tidak mengganggu jalannya pelayanan, kegiatan penyuluhan dilakukan kurang lebih 15 menit. Materi disesuaikan dengan topik masalah kesehatan pada hari itu dan jadwal yang sudah dibuat serta disampaikan ke pengunjung rawat jalan Puskesamas Songgon berpedoman pada SAP (Satuan Acara Penyuluhan) sehingga materi yang disampaikan cukup sesuai ${ }^{[7]}$.

Teknis dalam pelaksanaan inovasi program Penyu Raja yaitu dimulai dengan pembacaan hak dan kewajiban pasien, kemudian dilanjutkan dengan penyampaian materi penyuluhan. Penyuluhan diawali dengan ucapan salam dan perkelanan, selanjutnya penyampaian tujuan penyuluhan, kemudian menjelaskan pentingnya informasi kesehatan ini disampaikan atau penyampaian latar belakangnya ${ }^{[7]}$. Penyampaian materi penyuluhan yang sesuai dengan SAP (Satuan Acuan Penyuluhan) yang digunakan sebagai pedoman penyuluhan. Penggunaan bahasa yang disampaikan ke sasaran adalah bahasa awam atau bahasa sederhana sehari-hari sesuai dengan kondisi masyarakat di wilayah Kecamatan Songgon. Selain itu, metode yang digunakan untuk melakukan penyuluhan di rawat jalan ini adalah ceramah dan pemicuan. Role model juga memberikan leaflet sebagai media visual ke pengunjung pada saat penyuluhan, sehingga pengunjung tidak hanya mendengarkan ceramah saja tetapi juga dapat membaca informasi kesehatan dari leaflet yang dipegang. Media visual yang role model buat sendiri untuk mendukung media promosi kesehatan yakni leaflet terkait dengan Alat Kontrasepsi. Kemudian role model juga memanfaatkan fasilitas yang ada di Puskemas Songgon guna mendukung kegiatan promkes di Puskesmas, salah satunya yakni memanfaatkan televisi yang ada di ruang tunggu pelayanan rawat jalan guna memberikan edukasi/informasi kepada pengunjung terkait masalah 
kesehatan. Media audiovisual berupa video tentang kesehatan yang didapatkan dari beberapa tugas kuliah

\section{KESIMPULAN DAN SARAN}

Selama ini Puskesmas Songgon belum optimal dalam melakukan kegiatan promosi kesehatan di dalam gedung, yang ada hanya mengundanghadirkan sasaran untuk melasanakan kegiatan penyuluhan kesehatan di dalam gedung. Selain itu, belum adanya kegiatan penyuluhan di rawat jalan kepada pengunjung Puskesmas Songgon dan belum adanya pemanfaatan sumber daya yang ada di Puskesmas Songgon. Sehingga diperlukan adanya program inovasi Penyu Raja (Penyuluhan di Rawat Jalan) Puskesmas Songgon, sebagai salah satu bentuk upaya untuk meningkatkan promosi kesehatan didalam gedung. Pelaksanaan kegiatan dilakukan dengan secara stimulasi atau role model. Kegiatan ini mendapatkan respon yang baik oleh petugas kesehatan Puskesmas Songgon, hal ini terlihat dari tercapainya target $12(45 \%)$ petugas kesehatan yang mau dan

\section{DAFTAR PUSTAKA}

1. Departemen Kesehatan RI. 2017. Program Indonesia Sehat dengan Pendekatan Keluarga. Tersedia di: http://www.depkes.go.id [11 Maret 2019]

2. Keputusan Menteri Kesehatan Republik Indonesia Nomor 585 Tahun 2007 Tentang Pedoman Pelaksanaan Promosi Kesehatan di Puskesmas

3. Notoatmodjo, Soekidjo. 2010. Promosi Kesehatan: Teori dan Aplikasi. PT. Rineka Cipta: Jakarta.

4. Kementerian Kesehatan RI. 2015. Data dan Informasi: Profil dan beberapa dari Internet, tujuannya yakni sebagai media untuk melakukan promosi kesehatan di Puskesmas.

mampu melakukan penyuluhan di rawat jalan. Harapannya dapat menjadi acuan untuk pengambilan kebijakan terkait dengan penyuluhan di rawat jalan Puskesmas Songgon. Saran yang dapat kami berikan kepada pihak Puskesmas yakni: harapannya kepala Puskesmas dapat monitoring program inovasi ini, agar pemberdayaan petugas kesehatan di Puskesmas Songgon berjalan dengan baik. Selain itu, penanggungjawab program promosi kesehatan lebih sering mengingatkan rekan kerjanya (petugas kesehatan lainnya) untuk melaksanakan program inovasi ini. Harapannya petugas kesehatan dapat melanjutkan pemberdayaan ini dengan rutin sesuai dengan jadwal yang telah di tentukan. Kemudian saran berikutnya kami berikan kepada masyarakat atau pengunjung Puksesmas Songgon, harapannya lebih aktif bertanya saat dilakukan penyuluhan di rawat jalan oleh petugas kesehatan.

Kesehatan Indonesia 2014. Jakarta: Pusat Data dan Informasi. Tersedia di:

http://www.depkes.go.id/resources/ download/pusdatin/profil-

kesehatan-indonesia/profilkesehatan-indonesia-2014.pdf

5. Peraturan Menteri Kesehatan Republik Indonesia No. 2269 Tahun 2011 Tentang Pedoman Pembinaan Perilaku Hidup Bersih dan Sehat (PHBS)

6. Kementrian Kesehatan, Renstra Kementerian Kesehatan Tahun 2010-2014. Jakarta: Kementerian Kesehatan RI; 2010. 
7. Nurjannah. 2018. Laporan Monitoring dan Evaluasi Bulanan Kegiatan Program Promkes Bulan Desember 2018. Banyuwangi: Puskesmas Songgon Banyuwangi
8. World Health Organizations. 1986. Ottawa Charter For Health Promotion, www.who.int/hpr/NPH/docs/ottawa_c harter_hp.pdf, 07 Maret 2019 


\section{LAMPIRAN}

\section{Tabel [1]. Distribusi Sasaran Primer Pemberdayaan}

\begin{tabular}{llcc}
\hline No. & Petugas Kesehatan & N & \% \\
\hline 1. & Dokter & 2 & 7,4 \\
\hline 2. & Dokter Gigi & 1 & 3,7 \\
\hline 3. & Perawat & 5 & 18,5 \\
\hline 4. & Bidan & 15 & 55,6 \\
\hline 5. & Kesling & 1 & 3,7 \\
\hline 6. & Farmasi & 1 & 3,7 \\
\hline 7. & Ahli Gizi & 2 & 7,4 \\
\hline \multicolumn{2}{l}{ Total } & 27 & 100 \\
\hline \multicolumn{2}{l}{ Sumber: Profil Puskesmas Songgon Tahun 2017}
\end{tabular}

